Article

\title{
Variability in Human Mobility during the Third Wave of COVID-19 in Japan
}

\author{
Takafumi Ando*D, Toshihisa Sato, Naohisa Hashimoto, Yen Tran ${ }^{D}$, Naoki Konishi, Yuji Takeda \\ and Motoyuki Akamatsu
}

check for

updates

Citation: Ando, T.; Sato, T.;

Hashimoto, N.; Tran, Y.; Konishi, N.;

Takeda, Y.; Akamatsu, M. Variability in Human Mobility during the Third Wave of COVID-19 in Japan.

Sustainability 2021, 13, 13131. https://

doi.org/10.3390/su132313131

Academic Editors: Simona Tondelli and Elisa Conticelli

Received: 15 October 2021

Accepted: 23 November 2021

Published: 26 November 2021

Publisher's Note: MDPI stays neutral with regard to jurisdictional claims in published maps and institutional affiliations.

Copyright: (c) 2021 by the authors. Licensee MDPI, Basel, Switzerland. This article is an open access article distributed under the terms and conditions of the Creative Commons Attribution (CC BY) license (https:/ / creativecommons.org/licenses/by/ $4.0 /)$.
Human-Centered Mobility Research Center, Information Technology and Human Factors, National Institute of Advanced Industrial Science and Technology, Central 6, 1-1-1 Higashi, Tsukuba 305-8566, Japan; toshihisa-sato@aist.go.jp (T.S.); naohisa-hashimoto@aist.go.jp (N.H.); tran.yen@aist.go.jp (Y.T.); konishi-nk@aist.go.jp (N.K.); yuji-takeda@aist.go.jp (Y.T.); akamatsu-m@aist.go.jp (M.A.)

* Correspondence: takafumi.ando@aist.go.jp; Tel.: +81-29-861-2943

Abstract: Understanding factors regarding individual variability in human mobility during the COVID-19 pandemic would help inform future political and medical decisions. Particularly, understanding environmental factors would provide effective evidence for future urban development and the construction of a mobility service. Given the limited related evidence thus far, we investigated inter-individual variability in human mobility regarding life space during COVID-19 in Japan. We conducted an online survey to assess human mobility, demographics, and personality, and city structure surveys for objective environmental factors. Human mobility was assessed using the Life Space Assessment (LSA) questionnaire. Result revealed that the total LSA score was significantly higher in people who were men, middle-aged, working, living with their children, public transportation users, bicycle users, and car drivers, and those having a higher score for extraversion and ego resiliency and a lower score for conscientiousness. People living in the city with high traffic on the roads between plains and mountains had a higher LSA score, and had a lower score where there were many plains with a consistent road density, revealing diverse individual and environmental factors associated with human mobility during the pandemic. Thus, political decisions for urban development should consider these characteristics, the pandemic, and individual convenience.

Keywords: life space; human mobility; well-being; online survey; city structure; coronavirus disease 2019 (COVID-19); severe acute respiratory syndrome coronavirus-2 (SARS-CoV-2)

\section{Introduction}

A stretch of life space and sustainable transportation may contribute to the development of socio-economic activities, thus improving individuals' quality of life (QoL). However, after the outbreak of the coronavirus disease 2019 (COVID-19), socio-economic activities involving outings were restricted based on political and medical decisions to reduce infection spread in Japan and other countries. Such restrictions on outings and human mobility can consequently vary a person's QoL and subjective happiness. Indeed, the lockdown imposed due to COVID-19 has resulted in negative consequences for individuals' mental health and happiness [1-5].

Reduced human mobility would have a large inter-individual variability depending on individual environments, such as the residential area, occupation, family structure, etc., as well as personality, in line with results of studies before the COVID-19 pandemic, suggesting that human mobility was affected by these factors [6]. The variability might also lead to a difference in the risk of infection and other diseases, including mental illness and disabilities due to reduced life space and physical activity. Thus, understanding factors regarding individual variability in human mobility during the COVID-19 pandemic would help inform future political and medical decisions; specifically, to seek and control high-risk populations vulnerable to infection and other diseases and support those requiring help. 
Further, understanding both the types of environmental factors that unnecessarily increase human mobility and those that reduce human mobility and compensate for negative individual characteristics, would provide effective evidence for future urban development and the construction of a mobility service. However, evidence pertaining to these factors has been limited, at least in Japan.

Hanibuchi et al. (2021) [7] reported that specific individual and social characteristics such as younger people, women, unemployed individuals, those using public transportation, those with chronic diseases, individuals living in metropolitan areas, and those living with more than two people were associated with spending less time outside their homes. However, the sample size at different time points for each analysis was not abundant, and there was a lack of information in terms of the impact on a range of environments in which the individuals move within, and not only on the time spent outside their homes and/or the frequency of outings. Furthermore, the previous study has been limited in investigation of the neighborhood city structure.

Therefore, this study aimed to investigate the factors of inter-individual variability in human mobility in each range of life space environments during the COVID-19 pandemic in Japan. In addition, we conducted a cross-sectional analysis of the association between human mobility and subjective happiness.

\section{Methods}

\subsection{Smart Mobility Challenge}

This study was conducted as part of the nationwide project, "Smart Mobility Challenge." The Smart Mobility Challenge, which is led by the Ministry of Economy, Trade and Industry and the Ministry of Land, Infrastructure, Transport and Tourism, and initiated in 2019, aims at the social implementation of novel mobility services using the Internet of Things and artificial intelligence.

\subsection{Participants}

The study included samples from both online and city structure surveys. The full online dataset contained data from 13,000 participants aged 18-89 years in 15 areas (cities) of Japan. The sample sizes in each area were constructed to be equal to the proportion of the difference in the area-wise population. However, the number of participants with both datasets (i.e., online and city structure surveys) was 11,886 out of 13,000 . We then sampled the participants who were COVID-19 negative, with valid data on relevant variables for the study. In addition, the participants using walking aids and/or needing assistance from caregivers to move, as well as participants who did not leave their bedroom every day, were excluded to select healthy participants who could move freely, maintaining the reliability of the online data. The final dataset contained data from 7472 participants (Supplemental Figure S1).

\subsection{Online Survey}

The online survey was conducted by a subcontractor (VLC HOLDINGS CO., LTD., Tokyo, Japan) in the last week of January 2021 in 16 of the 52 areas where the Smart Mobility Challenge was implemented to understand the population's characteristics in those areas and the association between the convenience of transportation and human mobility, and subjective measures, including subjective satisfaction, QoL, and happiness. The subcontractor provided contracts to the survey participants, which included those relating to privacy protection, monetary compensation, and the consent to participate. We then obtained anonymous data under the contracts with the subcontractor. The online survey was conducted under an ethical manner of the human factors' ethical committee of the National Institute of Advanced Industrial Science and Technology.

The frequency of human mobility in each area of life space was assessed using the Japanese version of the Life Space Assessment (LSA) that was originally developed to assess the risk of long-term care in older adults [8]. For the LSA questionnaire, areas of 
human mobility ranged across five different levels (Figure 1): leaving a bedroom, an outing outside the house, an outing within the neighborhood ( $0-800 \mathrm{~m}$ from the house), an outing outside the neighborhood ( $0.8-16 \mathrm{~km}$ from the house), and an outing outside the town ( $\geq 16 \mathrm{~km}$ from the house). In this study, we used the frequency of human mobility in each area (1-4 points: 1, less than 1 time/week; 2, 1-3 times/week; 3, 4-6 times/week; 4 , everyday/week), as well as the total scores (the LSAtotal), without calculating the effect of walking aids and/or caregivers' assistance (the LSAtotal ranges between 0-60). Thus, the LSAtotal scores reflect the extent of human mobility and its frequency.

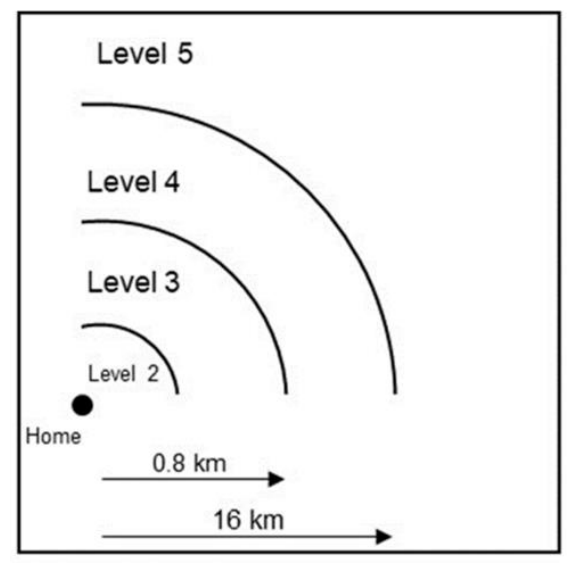

Figure 1. Level concepts of the life space assessment (LSA) questionnaire.

Personality was evaluated using the Japanese version of the Ten Item Personality Inventory (TIPI-J) [9,10] and the Ego Resiliency Scale (ER89) [11,12]. Anxiety about being infected with COVID-19 was assessed with the following question: How anxious do you feel about getting infected with COVID-19? Participants responded to this question using a 5-point Likert scale ranging from 1 (do not feel at all) to 5 (feel extremely). Subjective happiness was assessed using two tools: a Japanese version of the Subjective Happiness Scale (SHS) [13] that was originally developed by Lyubomirsky and Lepper in 1999 [14] and a sub-scale (general happiness, GH) of a Japanese version of the Subjective Well-being Inventory (SUBI) [15] which was originally developed by Nagpal and Sell in 1985 [16]. The SHS questionnaire contains four items scored on a 4-point Likert scale (ranged 1-4 points) [13]. The average SHS score of the individuals was calculated.

\subsection{City Structure Survey}

The city structure survey was conducted by a subcontractor (Nippon Koei Co., Ltd., Tokyo, Japan) in January 2021 in 15 areas, including 13 areas where the online-based survey was conducted. Statistical data on the living environment, such as the sufficiency rate for daily living services within walking distance, road network structures, and urban types (geography), were calculated using the National Land Numerical Information [17], the Digital Road Map database (Japan Digital Road Map Association, Tokyo, Japan), and traffic volume examinations, as listed in Table 2.

\subsection{Other Variables}

The total number of individuals who were infected with COVID-19 for a month up to the time of the online survey was calculated using prefecture's websites providing COVID-19 information for each relevant prefecture. We also used the variable of whether the areas were in a state of emergency (lockdown). Under the state of emergency, people were prohibited from unnecessary outings and crossing of prefectural boundaries.

\subsection{Statistical Analyses}

Prior to the analyses, all variables were tested for normal distribution based on kurtosis and skewness. Non-normally distributed variables were log-transformed. Gender 
differences, including gender interactions, were tested using a chi-square test for categorical variables and a $t$-test for numeric variables. Associations of measures of LSA with potential factors, such as personality, environmental, and demographic factors, were analyzed using general linear models. General linear models were also used to investigate the associations of measures of LSA with SHS and GH, with adjustments for potential covariates. For all models, the inclusion of variables was based on the hypotheses of the present study. All statistical analyses were performed using SAS Enterprise Guide 8.3 (SAS Institute Inc., Cary, NC, USA). The $p$-value was considered significant at 0.05 . Data were presented as mean $\pm \mathrm{SD}$, unless otherwise indicated.

\section{Results}

\subsection{Participants' Characteristics and Geographic Characteristics of Cities}

The participants' characteristics are displayed in Table 1. Except for marital and car status (shared family cars), there was a significant difference in the mean values of variables between gender and the proportion of gender in the other variables. The LSA measures were higher among men than women (all $p<0.0001)$, whereas both happiness scales were higher among women than men (both $p<0.0001$ ).

A summary of the geographic characteristics is presented in Table 2. The population of each relevant area ranged from 18,297 to 799,598 . The population density of each relevant area ranged from 27.4 people $/ \mathrm{km}^{2}$ to 5996.2 people $/ \mathrm{km}^{2}$; in brief, our study included data ranging from a small city in a rural area to a big city in a metropolitan suburban area. During the online survey, three areas were in a state of emergency.

Table 1. Characteristics of participants.

\begin{tabular}{|c|c|c|c|c|c|}
\hline \multicolumn{2}{|c|}{ Variables } & Mean \pm SD & 25th Percentile & 75th Percentile & $\begin{array}{l}\text { P for Gender } \\
\text { Difference * }\end{array}$ \\
\hline \multicolumn{2}{|c|}{ N (\% women) } & & 7472 (46.9\%) & & \\
\hline \multirow{13}{*}{ Residential areas } & Kitahiroshima & & $154(52.6 \%)$ & & \multirow{13}{*}{$<0.0001$} \\
\hline & Niigata & & $1477(47.4 \%)$ & & \\
\hline & Tsukuba & & $478(52.6 \%)$ & & \\
\hline & Machida & & $989(42.6 \%)$ & & \\
\hline & Shiojiri & & $145(49.0 \%)$ & & \\
\hline & Shizuoka & & $1342(49.3 \%)$ & & \\
\hline & Kosai & & $128(35.2 \%)$ & & \\
\hline & Hamamatsu & & $1646(44.8 \%)$ & & \\
\hline & Bisan-chiku & & $916(52.4 \%)$ & & \\
\hline & Eiheiji & & $35(54.3 \%)$ & & \\
\hline & Yabu & & $26(26.9 \%)$ & & \\
\hline & Shobara & & $36(52.8 \%)$ & & \\
\hline & Mitoyo & & $100(46.0 \%)$ & & \\
\hline \multirow{7}{*}{ Age } & $18-29$ years & & $694(72.6 \%)$ & & \multirow{7}{*}{$<0.0001$} \\
\hline & 30-39 years & & 1547 (69.4\%) & & \\
\hline & $40-49$ years & & $1977(46.4 \%)$ & & \\
\hline & $50-59$ years & & $1813(36.0 \%)$ & & \\
\hline & $60-69$ years & & $995(25.2 \%)$ & & \\
\hline & $70-79$ years & & $403(25.0 \%)$ & & \\
\hline & $80-89$ years & & $43(18.6 \%)$ & & \\
\hline
\end{tabular}


Table 1. Cont.

\begin{tabular}{|c|c|c|c|c|c|c|}
\hline \multicolumn{2}{|c|}{ Variables } & Mean \pm SD & 25th Percentile & 50th Percentile & 75th Percentile & $\begin{array}{l}P \text { for Gender } \\
\text { Difference * }\end{array}$ \\
\hline \multirow{4}{*}{ Occupation } & Working & \multicolumn{4}{|c|}{$5628(41.0 \%)$} & \multirow{4}{*}{$<0.0001$} \\
\hline & Household manager & \multicolumn{4}{|c|}{$955(98.1 \%)$} & \\
\hline & Student & \multicolumn{4}{|c|}{$124(66.9 \%)$} & \\
\hline & Not working & \multicolumn{4}{|c|}{$765(23.3 \%)$} & \\
\hline \multirow{6}{*}{ Household income } & Less than 2.01 million yen & \multicolumn{4}{|c|}{$747(60.8 \%)$} & \multirow{6}{*}{$<0.0001$} \\
\hline & 2.01-4.00 million yen & \multicolumn{4}{|c|}{$1641(48.9 \%)$} & \\
\hline & 4.01-6.00 million yen & \multicolumn{4}{|c|}{$1813(49.4 \%)$} & \\
\hline & $6.01-8.00$ million yen & \multicolumn{4}{|c|}{$1447(44.4 \%)$} & \\
\hline & 8.01-10.00 million yen & \multicolumn{4}{|c|}{$919(42.3 \%)$} & \\
\hline & More than 10 million yen & \multicolumn{4}{|c|}{$905(35.7 \%)$} & \\
\hline \multirow{2}{*}{ Marital status } & Single & \multicolumn{4}{|c|}{$2184(48.6 \%)$} & \multirow{2}{*}{0.06} \\
\hline & Married & \multicolumn{4}{|c|}{$5288(46.2 \%)$} & \\
\hline \multirow{3}{*}{ Child status } & No & \multicolumn{4}{|c|}{$2637(48.2 \%)$} & \multirow{3}{*}{$<0.0001$} \\
\hline & Yes, not living with & & & $(32.2 \%)$ & & \\
\hline & Yes, living with & & & (51.1\%) & & \\
\hline \multirow[b]{2}{*}{ Car status (owned cars) } & No & \multicolumn{4}{|c|}{$2681(55.2 \%)$} & \multirow[b]{2}{*}{$<0.0001$} \\
\hline & $\begin{array}{l}\text { Yes, I own a car that } \\
\text { I can use }\end{array}$ & \multicolumn{4}{|c|}{$4791(42.3 \%)$} & \\
\hline \multirow{2}{*}{$\begin{array}{l}\text { Car status (shared } \\
\text { family cars) }\end{array}$} & No & \multicolumn{4}{|c|}{$5027(46.4 \%)$} & \\
\hline & $\begin{array}{l}\text { Yes, my family owns a } \\
\text { car that I can use }\end{array}$ & \multicolumn{4}{|c|}{$2445(48.1 \%)$} & 0.1753 \\
\hline Public transportation & Never & & 604 & $(47.9 \%)$ & & \\
\hline $\begin{array}{l}\text { use (train, bus, taxi) in } \\
\text { the past } 4 \text { weeks }\end{array}$ & $\begin{array}{l}\text { Used more than or } \\
\text { equal to once }\end{array}$ & & & $(43.0 \%)$ & & 0.001 \\
\hline & Never & & 584 & $(48.1 \%)$ & & \\
\hline past 4 weeks & $\begin{array}{l}\text { Used more than or } \\
\text { equal to once }\end{array}$ & & & $(42.6 \%)$ & & $<0.0001$ \\
\hline Car driving in the & Never & & & $(55.2 \%)$ & & \\
\hline past 4 weeks & $\begin{array}{l}\text { Used more than or } \\
\text { equal to once }\end{array}$ & & 552 & $(44.0 \%)$ & & $<0.0001$ \\
\hline Car riding as a & Never & & & $(66.6 \%)$ & & \\
\hline $\begin{array}{l}\text { passenger in the } \\
\text { past } 4 \text { weeks }\end{array}$ & $\begin{array}{l}\text { Used more than or } \\
\text { equal to once }\end{array}$ & & & $(40.6 \%)$ & & $<0.0001$ \\
\hline & Total $(0-60)$ & $43.2 \pm 12.1$ & 36 & 43 & 51 & $\begin{array}{l}<0.0001 \\
\mathrm{~W}<\mathrm{M}\end{array}$ \\
\hline & $\begin{array}{c}\text { Level } 2(1-4, \\
\text { discrete variable) }\end{array}$ & $3.8 \pm 0.5$ & 4 & 4 & 4 & $\begin{array}{l}<0.0001 \\
\mathrm{~W}<\mathrm{M}\end{array}$ \\
\hline $\begin{array}{l}\text { Life space score in the } \\
\text { past } 4 \text { weeks }\end{array}$ & $\begin{array}{c}\text { Level } 3(1-4, \\
\text { discrete variable) }\end{array}$ & $3.4 \pm 0.8$ & 3 & 4 & 4 & $\begin{array}{l}<0.0001 \\
\mathrm{~W}<\mathrm{M}\end{array}$ \\
\hline & $\begin{array}{c}\text { Level } 4(1-4, \\
\text { discrete variable) }\end{array}$ & $2.9 \pm 1.1$ & 2 & 3 & 4 & $\begin{array}{l}<0.0001 \\
\mathrm{~W}<\mathrm{M}\end{array}$ \\
\hline & $\begin{array}{c}\text { Level } 5(1-4, \\
\text { discrete variable) }\end{array}$ & $1.8 \pm 1.4$ & 1 & 2 & 3 & $\begin{array}{l}<0.0001 \\
\mathrm{~W}<\mathrm{M}\end{array}$ \\
\hline $\begin{array}{l}\text { Anxiety about getting } \\
\text { infected with the } \\
\text { COVID-19 }\end{array}$ & (1-5, discrete variable) & $3.3 \pm 1.2$ & 2 & 3 & 4 & $\begin{array}{l}<0.0001 \\
\mathrm{~W}>\mathrm{M}\end{array}$ \\
\hline
\end{tabular}


Table 1. Cont.

\begin{tabular}{|c|c|c|c|c|c|c|}
\hline & ables & Mean \pm SD & 25th Percentile & 50th Percentile & 75th Percentile & $\begin{array}{l}\text { P for Gender } \\
\text { Difference * }\end{array}$ \\
\hline \multirow{6}{*}{ Personality } & Extraversion (TIPI-J) & $7.4 \pm 2.5$ & 6 & 8 & 9 & $\begin{array}{l}<0.0001 \\
\mathrm{~W}>\mathrm{M}\end{array}$ \\
\hline & Agreeableness (TIPI-J) & $9.6 \pm 2.1$ & 8 & 10 & 11 & $\begin{array}{l}0.0006 \\
\mathrm{~W}>\mathrm{M}\end{array}$ \\
\hline & Openness (TIPI-J) & $7.7 \pm 2.3$ & 6 & 8 & 9 & $\begin{array}{l}<0.0001 \\
\mathrm{~W}<\mathrm{M}\end{array}$ \\
\hline & Conscientiousness (TIPI-J) & $7.9 \pm 2.4$ & 6 & 8 & 10 & $\begin{array}{l}<0.0001 \\
\mathrm{~W}<\mathrm{M}\end{array}$ \\
\hline & Neuroticism (TIPI-J) & $8.1 \pm 2.4$ & 7 & 8 & 10 & $\begin{array}{l}<0.0001 \\
\mathrm{~W}>\mathrm{M}\end{array}$ \\
\hline & Ego resiliency (ER89) & $34.1 \pm 7.0$ & 30 & 34 & 39 & $\begin{array}{c}0.009 \\
\mathrm{~W}<\mathrm{M}\end{array}$ \\
\hline \multirow{2}{*}{ Subjective happiness } & $\begin{array}{l}\text { Subjective Happiness } \\
\text { Scale, averaged (1-4) }\end{array}$ & $2.63 \pm 0.61$ & 2.25 & 2.75 & 3.00 & $\begin{array}{l}<0.0001 \\
\mathrm{~W}>\mathrm{M}\end{array}$ \\
\hline & $\begin{array}{l}\text { General happiness, } \\
\text { averaged (1-3) }\end{array}$ & $1.95 \pm 0.39$ & 1.67 & 2.00 & 2.22 & $\begin{array}{l}<0.0001 \\
\mathrm{~W}>\mathrm{M}\end{array}$ \\
\hline
\end{tabular}

* Gender differences, including gender interactions, were tested using a chi-square test for categorical variables and a t-test for numeric variables. With the results of the $t$-test, the magnitude of the difference in mean values (i.e., higher or lower [greater or lesser]) between genders was expressed by a sign of inequality. The TIPI-J is a ten-item personality inventory. The ER89 is an ego resiliency questionnaire.

Table 2. Characteristics of city structures.

\begin{tabular}{|c|c|c|}
\hline & Variables & Mean \pm SD/Number \\
\hline \multirow{8}{*}{$\begin{array}{l}\text { Area characteristics } \\
\text { for a living } \\
\text { environment }\end{array}$} & Sufficiency rate for daily living services within walking distance $(\leq 0.8 \mathrm{~km}), \%$ & $25.5 \pm 17.8$ \\
\hline & Coverage of population within walking distance $(\leq 0.8 \mathrm{~km})$ from medical facilities, $\%$ & $73.7 \pm 18.9$ \\
\hline & Coverage of population within walking distance $(\leq 0.8 \mathrm{~km})$ from welfare facilities, $\%$ & $74.9 \pm 20.2$ \\
\hline & Coverage of population within walking distance $(\leq 0.8 \mathrm{~km})$ from commercial facilities, $\%$ & $54.9 \pm 19.6$ \\
\hline & $\begin{array}{c}\text { Coverage of population within walking distance }(\leq 0.8 \mathrm{~km}) \text { from core public } \\
\text { transportation routes }(\geq 30 \text { available } / \text { daily }), \%\end{array}$ & $34.7 \pm 21.2$ \\
\hline & $\begin{array}{l}\text { Population density in areas around train stations }(\leq 0.8 \mathrm{~km}) \text { or bus stops }(\leq 0.3 \mathrm{~km}) \\
\text { for public transportation lines, people } / \mathrm{ha}\end{array}$ & $20.0 \pm 18.5$ \\
\hline & $\begin{array}{l}\text { Insufficiency rate for medical facilities within walking distance }(\leq 0.8 \mathrm{~km}) \text { from housing } \\
\text { occupied by the elderly population }(\geq 65 \text { years }), \%\end{array}$ & $58.4 \pm 19.2$ \\
\hline & $\begin{array}{c}\text { Coverage of the elderly population }(\geq 65 \text { years) within } 1 \mathrm{~km} \text { from elderly } \\
\text { welfare facilities, } \%\end{array}$ & $78.9 \pm 20.0$ \\
\hline \multirow{5}{*}{$\begin{array}{l}\text { Urban types } \\
\text { (number of areas) }\end{array}$} & A, there are many mountainous areas and road density at hubs is relatively low. & 3 areas \\
\hline & $\mathrm{B}$, there are plains and mountains, and road links are concentrated in the plains. & 1 area \\
\hline & C, hubs with high road density are dispersed. & 4 areas \\
\hline & $\mathrm{D}$, there are many plains and road density is almost consistent. & 4 areas \\
\hline & E, the traffic on the roads between plains and mountains is high. & 1 area \\
\hline
\end{tabular}

Note. Sufficiency rate for daily living services within walking distance $(\leq 0.8 \mathrm{~km})$, the proportion of people who can access all the daily living services (including medical, welfare, and commercial facilities, and core public transportation routes) by walking; coverage of population within walking distance $(\leq 0.8 \mathrm{~km})$ from medical facilities, the proportion of people who can access medical facilities (a hospital for internal medicine or surgery, a clinic) by walking; coverage of population within walking distance $(\leq 0.8 \mathrm{~km})$ from welfare facilities, the proportion of people who can access welfare facilities by walking; coverage of population within walking distance $(\leq 0.8 \mathrm{~km})$ from commercial facilities, the proportion of people who can access commercial facilities (a supermarket, a department store) by walking; coverage of population within walking distance $(\leq 0.8 \mathrm{~km})$ from core public transportation routes $(\geq 30$ available /daily), the proportion of people who can access core public transportation stations (railway or bus with more than 30 operations per day) by walking; insufficiency rate for medical facilities within walking distance $(\leq 0.8 \mathrm{~km})$ from housing occupied by the elderly population $(\geq 65$ years), the proportion of housing that is not within walking distance for elderly people $(\leq 0.8 \mathrm{~km})$ from the medical facilities; coverage of the elderly population ( $\geq 65$ years) within $1 \mathrm{~km}$ from elderly welfare facilities, the proportion of elderly people who live within $1 \mathrm{~km}$ from the welfare facilities. 


\subsection{Individual Factors of Human Mobility during the Pandemic}

The results of the individual factors, such as age, gender, and occupation, of the LSAtotal are shown in Table 3. Regarding the demographic factors, male gender, public transportation use, bicycle riding, and car driving contributed to a higher LSAtotal score (Table 3). Further, people aged 40-59 years had a higher LSAtotal score compared to those aged 18-39 years even after a multiple comparison correction with the Tukey-Kramer method (all $p<0.05$, Figure 2A). People who were working had the highest LSAtotal score (all $p<0.05$, Figure 2B) and LSA at levels 2-5 among the occupations. People who were living with their children had a higher LSAtotal score $(p=0.0056$, Figure 2C) and LSA at levels $2-4(p<0.05)$ regarding the child status even after a multiple comparison correction with the Tukey-Kramer method. People aged 18-29 years had the lowest scores, whereas those aged 70-79 years had the highest LSA scores at levels $2-4$. However, at level 5, people aged 50-59 years had the highest LSA score, and there was a significant difference between individuals aged $30-39$ years and those aged 50-59 $(p=0.0086)$.

Table 3. Association of potential variables in relation to individual factors with a score of LSAtotal.

\begin{tabular}{|c|c|c|c|c|c|}
\hline Variables & & $\beta$ & SE & Standardized $\beta$ & $p$-Value \\
\hline Intercept & & 26.35 & 1.75 & & $<0.0001$ \\
\hline \multirow[t]{2}{*}{ Gender } & Women & 0 (ref.) & & & $<0.0001$ \\
\hline & Men & 2.12 & 0.32 & & \\
\hline \multirow[t]{7}{*}{ Age } & $18-29$ years & 0 (ref.) & & & $<0.0001$ \\
\hline & 30-39 years & 0.46 & 0.55 & & \\
\hline & 40-49 years & 1.79 & 0.55 & & \\
\hline & 50-59 years & 2.27 & 0.56 & & \\
\hline & 60-69 years & 1.52 & 0.66 & & \\
\hline & $70-79$ years & 2.40 & 0.86 & & \\
\hline & $80-89$ years & 0.97 & 1.84 & & \\
\hline \multirow[t]{4}{*}{ Occupation } & Not working & 0 (ref.) & & & $<0.0001$ \\
\hline & Working & 7.22 & 0.52 & & \\
\hline & Household manager & 1.71 & 0.65 & & \\
\hline & Student & 3.32 & 1.21 & & \\
\hline \multirow[t]{6}{*}{ Household income } & Less than 2.01 million yen & 0 (ref.) & 0.00 & & 0.1768 \\
\hline & 2.01-4.00 million yen & 0.73 & 0.51 & & \\
\hline & 4.01-6.00 million yen & 1.13 & 0.52 & & \\
\hline & $6.01-8.00$ million yen & 1.28 & 0.55 & & \\
\hline & 8.01-10.00 million yen & 0.52 & 0.60 & & \\
\hline & More than 10 million yen & 0.98 & 0.61 & & \\
\hline \multirow[t]{2}{*}{ Marital status } & No & 0 (ref.) & & & 0.9573 \\
\hline & Yes & -0.02 & 0.39 & & \\
\hline \multirow[t]{3}{*}{ Child status } & No & 0 (ref.) & & & 0.0059 \\
\hline & Yes, not living with & 0.42 & 0.47 & & \\
\hline & Yes, living with & 1.12 & 0.36 & & \\
\hline \multirow[t]{2}{*}{$\begin{array}{c}\text { Car status } \\
\text { (owned cars) }\end{array}$} & No & 0 (ref.) & & & 0.0005 \\
\hline & Yes, I own a car that I can use & 1.48 & 0.43 & & \\
\hline
\end{tabular}


Table 3. Cont.

\begin{tabular}{|c|c|c|c|c|c|}
\hline Variables & & $\beta$ & SE & Standardized $\beta$ & $p$-Value \\
\hline \multirow[t]{2}{*}{$\begin{array}{c}\text { Car status } \\
\text { (shared family cars) }\end{array}$} & No & 0 (ref.) & & & 0.1955 \\
\hline & $\begin{array}{l}\text { Yes, my family owns a car } \\
\text { that I can use }\end{array}$ & -0.50 & 0.39 & & \\
\hline \multirow[t]{2}{*}{$\begin{array}{l}\text { Public transportation } \\
\text { use in the past } 4 \text { weeks }\end{array}$} & Never & 0 (ref.) & & & $<0.0001$ \\
\hline & Used more than or equal to once & 3.11 & 0.36 & & \\
\hline \multirow[t]{2}{*}{$\begin{array}{l}\text { Bicycle riding in the } \\
\text { past } 4 \text { weeks }\end{array}$} & Never & 0 (ref.) & & & $<0.0001$ \\
\hline & Used more than or equal to once & 1.45 & 0.32 & & \\
\hline \multirow[t]{2}{*}{$\begin{array}{l}\text { Car driving in the } \\
\text { past } 4 \text { weeks }\end{array}$} & Never & 0 (ref.) & & & $<0.0001$ \\
\hline & Used more than or equal to once & 5.05 & 0.35 & & \\
\hline \multirow{2}{*}{$\begin{array}{l}\text { Car riding as a } \\
\text { passenger in the } \\
\text { past } 4 \text { weeks }\end{array}$} & Never & 0 (ref.) & & & 0.7587 \\
\hline & Used more than or equal to once & -0.10 & 0.32 & & \\
\hline \multirow[t]{13}{*}{ Areas } & Kitahiroshima & 0 (ref.) & & & $<0.0001$ \\
\hline & Niigata & 0.14 & 0.94 & & \\
\hline & Tsukuba & -1.69 & 1.03 & & \\
\hline & Machida & -0.73 & 0.96 & & \\
\hline & Shiojiri & -1.39 & 1.28 & & \\
\hline & Shizuoka & -0.56 & 0.94 & & \\
\hline & Kosai & -0.72 & 1.33 & & \\
\hline & Hamamatsu & 0.59 & 0.94 & & \\
\hline & Bisan-chiku & 1.86 & 0.97 & & \\
\hline & Eiheiji & 4.26 & 2.08 & & \\
\hline & Yabu & 2.29 & 2.35 & & \\
\hline & Shobara & 0.17 & 2.05 & & \\
\hline & Mitoyo & 3.48 & 1.43 & & \\
\hline $\begin{array}{l}\text { Anxiety about getting } \\
\text { infected with COVID-19 }\end{array}$ & & -0.13 & 0.11 & & 0.2178 \\
\hline \multirow[t]{6}{*}{ Personality } & Extraversion (TIPI-J) & 0.64 & 0.12 & 0.06561 & $<0.0001$ \\
\hline & Agreeableness (TIPI-J) & -0.19 & 0.14 & -0.01657 & 0.1635 \\
\hline & Openness (TIPI-J) & 0.00 & 0.13 & -0.00025 & 0.9844 \\
\hline & Conscientiousness (TIPI-J) & -0.32 & 0.12 & -0.03222 & 0.0078 \\
\hline & Neuroticism (TIPI-J) & -0.03 & 0.13 & -0.00252 & 0.8462 \\
\hline & Ego resiliency (ER89) & 0.80 & 0.34 & 0.03314 & 0.0168 \\
\hline
\end{tabular}

LSAtotal, the total score of the life space assessment questionnaire. The TIPI-J is a ten-item personality inventory; the ER89 is an ego resiliency questionnaire. The statistics of all these variables were considered to be interrelated using the general linear model. 
A

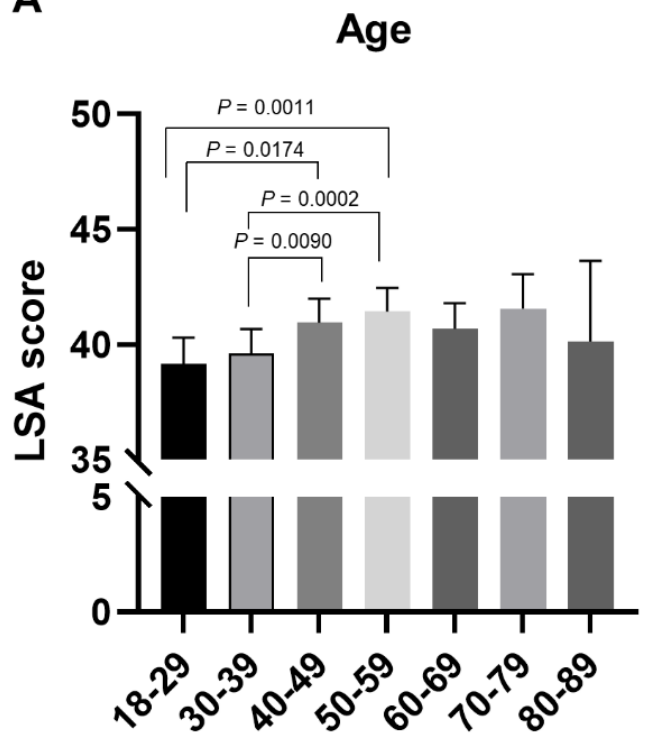

B

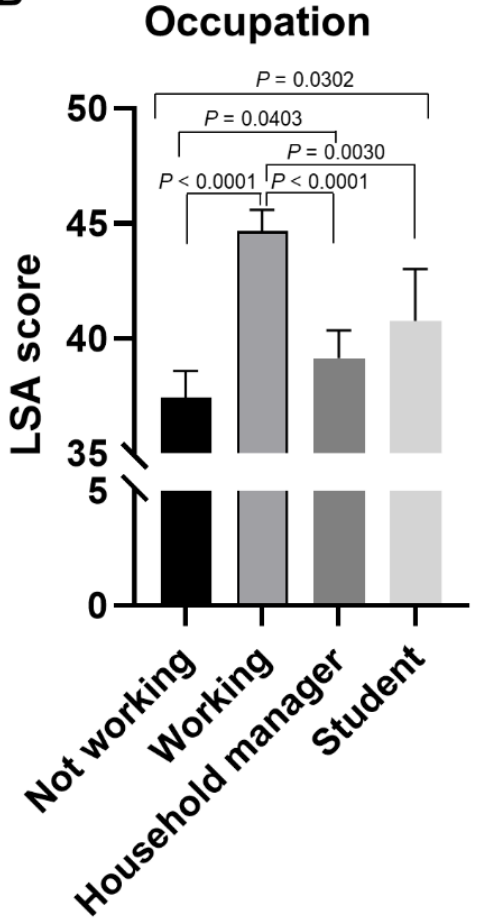

C

\section{Child status}

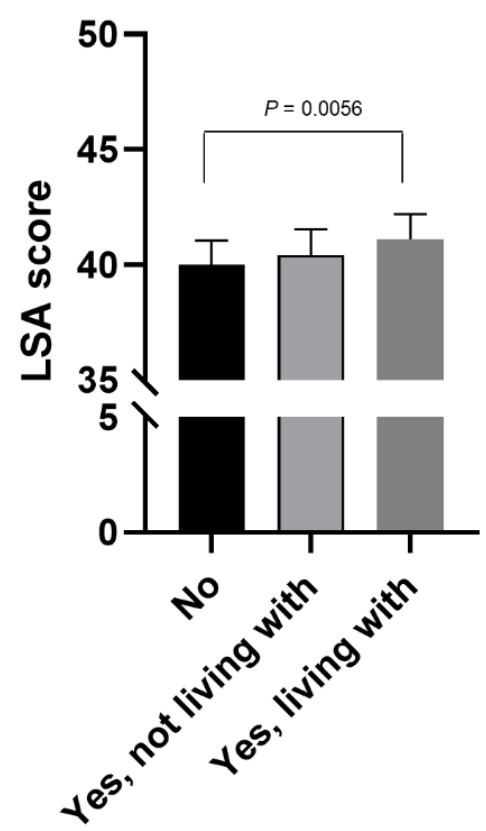

Figure 2. Effective categorical variables for life space assessment (LSA) scores. (A), associations of age categories with LSAtotal scores; (B), associations of occupations with LSAtotal scores; (C), associations of child status with LSAtotal scores. Bar graphs and error bars indicate mean and $95 \% \mathrm{Cl}$ in each category. Statistical analyses were performed using the general linear model with multiple comparison correction of the Tukey-Kramer method.

In addition, at levels 2-4 of LSA, vehicle use, including public transportation use, bicycle riding, and car driving contributed to a higher LSA score (all $p<0.05$ ); however, bicycle riding's contribution disappeared at level 5 , although the contribution of the other variables still appeared at level 5 . At levels 3-5 of LSA, men had a higher LSA score (all $p<0.05$ ). At level 5 of LSA, owning cars significantly contributed to a higher LSA score (all $p<0.0001$ ).

Regarding personality factors, extraversion and ego resiliency scores were positively associated with scores of LSAtotal and LSA at levels 2 and 5 , whereas the conscientiousness score was negatively associated with LSAtotal and LSA at levels 3 and 5 (all $p<0.05$ ). At level 4 of the LSA, only extraversion had a positive effect on the LSA score $(p=0.0013)$.

\subsection{Environmental Factors of Human Mobility during the Pandemic}

The LSAtotal of the environmental factors, such as the area characteristics for the living environment and urban types, are shown in Table 4 . Each factor (i.e., area characteristics for the living environment and urban types) was independently analyzed as solely determining the area characteristics to prevent multicollinearity between variables.

In terms of the area characteristics for a living environment, each sub-variable was also analyzed separately. The sufficiency rate for daily living services within walking distance (Standardized $\beta=-0.045, p<0.0001$ ), the population coverage within walking distance from welfare facilities (Standardized $\beta=-0.039, p=0.0003$ ), and the population coverage within walking distance from core public transportation routes (Standardized $\beta=-0.053$, $p<0.0001$ ) were negatively associated with the LSAtotal, while the insufficiency rate for medical facilities within walking distance from housing occupied by the elderly population (Standardized $\beta=0.045, p<0.0001$ ) was positively associated with the LSAtotal. For the LSA scores at each level, the sufficiency rate for daily living services within walking distance was negatively associated with the LSA scores at levels 4 (Standardized $\beta=-0.027$, $p=0.0176$ ) and 5 (Standardized $\beta=-0.057, p<0.0001$ ), the population coverage within 
walking distance from welfare facilities was negatively associated with the LSA score at level 5 (Standardized $\beta=-0.060, p<0.0001$ ), and the population coverage within walking distance from commercial facilities was positively associated with the LSA score at level 5 (Standardized $\beta=0.024, p=0.0371$ ). Similarly, the population coverage within walking distance from core public transportation routes was negatively associated with the LSA scores at levels 4 (Standardized $\beta=-0.025, p=0.0303$ ) and 5 (Standardized $\beta=-0.075$, $p<0.0001)$; the population density in areas around train stations or bus stops for public transportation lines was negatively associated with the LSA scores at levels 2 (Standardized $\beta=-0.025, p=0.0346$ ), 3 (Standardized $\beta=-0.041, p=0.0005$ ), and 4 (Standardized $\beta=-0.042, p=0.0003)$; and the insufficiency rate for medical facilities within walking distance from housing occupied by the elderly was positively associated with the LSA scores at level 5 (Standardized $\beta=0.064, p<0.0001$ ).

Table 4. Association of potential variables in relation to environmental factors with a score of LSAtotal.

\begin{tabular}{|c|c|c|c|c|c|}
\hline Variables & & $\beta$ & SE & Standardized $\beta$ & $p$-Value \\
\hline \multirow[t]{8}{*}{$\begin{array}{l}\text { Area } \\
\text { characteristics for a } \\
\text { living environment }\end{array}$} & $\begin{array}{l}\text { Sufficiency rate for daily living services within } \\
\text { walking distance }\end{array}$ & -0.03457 & 0.008597 & -0.04495 & $<0.0001$ \\
\hline & $\begin{array}{c}\text { Coverage of population within walking distance } \\
\text { from medical facilities }\end{array}$ & 0.019669 & 0.013833 & 0.01539 & 0.1551 \\
\hline & $\begin{array}{c}\text { Coverage of population within walking distance } \\
\text { from welfare facilities }\end{array}$ & -0.05414 & 0.015113 & -0.03913 & 0.0003 \\
\hline & $\begin{array}{l}\text { Coverage of population within walking distance } \\
\text { from commercial facilities }\end{array}$ & 0.006296 & 0.009949 & 0.00700 & 0.5269 \\
\hline & $\begin{array}{l}\text { Coverage of population within walking distance } \\
\text { from core public transportation routes }\end{array}$ & -0.03911 & 0.008156 & -0.05302 & $<0.0001$ \\
\hline & $\begin{array}{l}\text { Population density in areas around train stations } \\
\text { or bus stops for public transportation lines }\end{array}$ & -0.01044 & 0.008058 & -0.01481 & 0.1949 \\
\hline & $\begin{array}{c}\text { Insufficiency rate for medical facilities within } \\
\text { walking distance from housing occupied by the } \\
\text { elderly population }\end{array}$ & 0.038481 & 0.009335 & 0.04530 & $<0.0001$ \\
\hline & $\begin{array}{c}\text { Coverage of elderly population within } 1 \mathrm{~km} \text { from } \\
\text { elderly welfare facilities }\end{array}$ & -0.00931 & 0.016956 & -0.00597 & 0.5829 \\
\hline \multirow[t]{5}{*}{ Urban types } & $\begin{array}{c}\text { A, there are many mountainous areas and road } \\
\text { density at hubs is relatively low. }\end{array}$ & 0 & & & $<0.0001$ \\
\hline & $\begin{array}{l}\mathrm{B} \text {, there are plains and mountains, and road links } \\
\text { are concentrated in the plains. }\end{array}$ & -1.60563 & 1.158558 & & \\
\hline & C, hubs with high road density are dispersed. & -1.14805 & 1.16633 & & \\
\hline & $\begin{array}{l}\mathrm{D} \text {, there are many plains and road density is } \\
\text { almost consistent. }\end{array}$ & -2.66032 & 1.141038 & & \\
\hline & $\begin{array}{l}\text { E, the traffic on the roads between plains and } \\
\text { mountains is high. }\end{array}$ & 1.275508 & 1.576864 & & \\
\hline
\end{tabular}

These variables were adjusted for the variables in Table 3, except for the area-related variables. LSAtotal, the total score of the life space assessment questionnaire.

For the urban types, after multiple comparison correction with the Tukey-Kramer method (Figure 3), people living in the area where there were many plains and where road density was almost consistent had the lowest LSAtotal score, whereas people living in the area where traffic on the roads between plains and mountains was high had the highest LSAtotal score. For the LSA score at level 5, the relationships among urban types were almost consistent with those of the LSAtotal. However, for levels 2 and 3, the LSA score of people living in the area where there were plains and mountains, and where road links were concentrated in the plains, was higher than in the area where hubs with high road density were dispersed. 

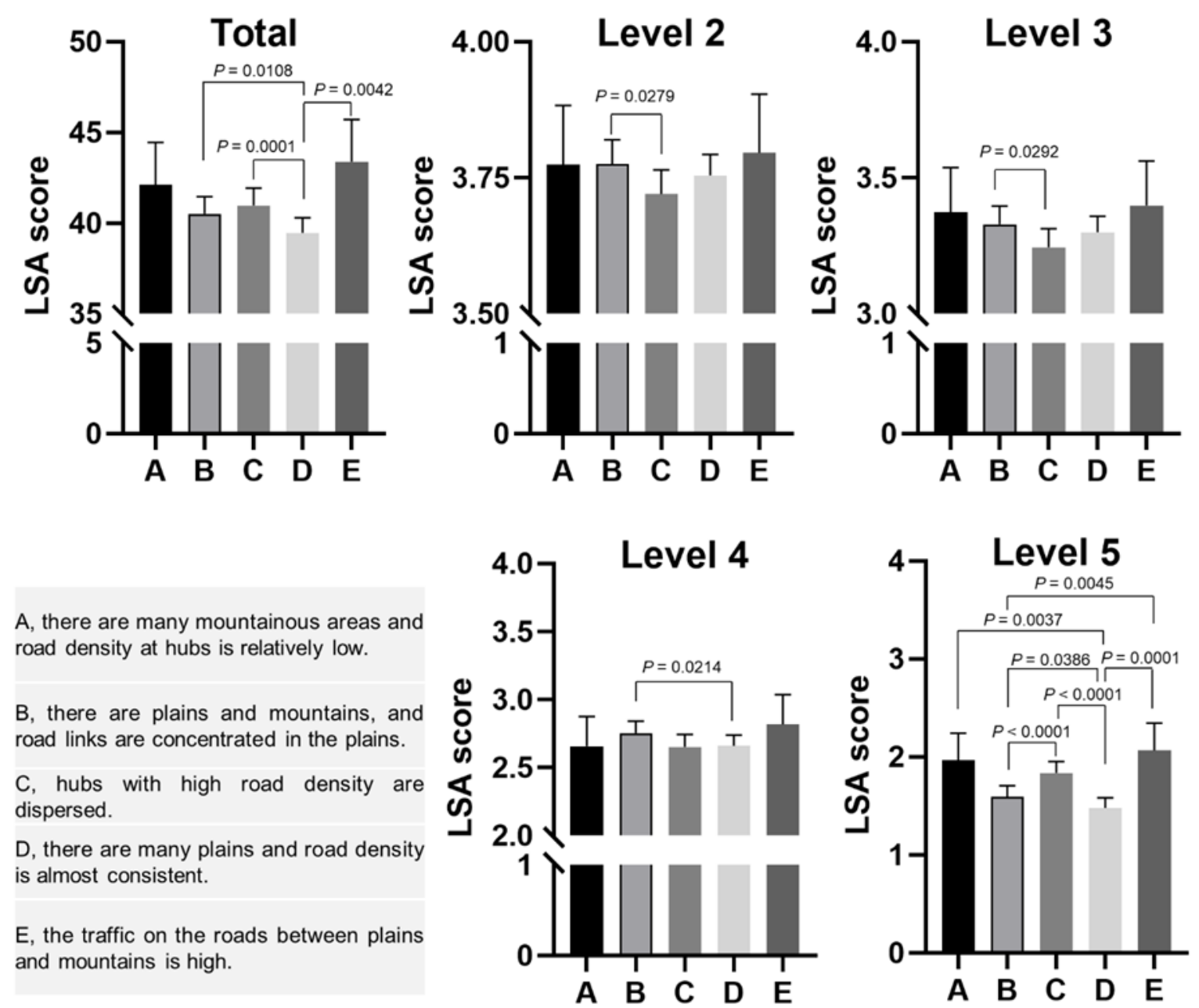

Figure 3. Associations of urban types with measures of human mobility. Bar graphs and error bars indicate mean and $95 \%$ $\mathrm{Cl}$ in each category. Statistical analyses were performed using the general linear model with multiple comparison correction of the Turkey-Kramer method.

\subsection{COVID-19-Related Factors of Human Mobility during the Pandemic}

Anxiety about getting infected with COVID-19 was associated with a lower LSA score only at level 3 ( $\beta=-0.0167$, Standardized $\beta=-0.0247, p=0.0287$ ), after the adjustment of potential covariates, including the variable "areas."

Relevant analyses were performed for the independent variables below by replacing them with variable "areas." The state of emergency was associated with higher LSAtotal scores $(\beta=0.7108, p=0.0198$, Figure 4A) and LSA at level $5(\beta=0.2753, p<0.0001$, Figure $4 \mathrm{E})$, whereas the state of emergency was associated with a lower LSA score at levels 2 ( $\beta=-0.0354, p=0.0123$, Figure $4 \mathrm{~B}), 3(\beta=-0.0918, p<0.0001$, Figure $4 \mathrm{C})$, and $4(\beta=-0.0799, p=0.0054$, Figure $4 \mathrm{D})$.

The log-transformed number of new COVID-19 cases in the past month in the prefecture where the relevant area was located had no association with LSAtotal scores ( $\beta=-0.0586$, Standardized $\beta=-0.0069, p=0.5398)$ and LSA at level $2(\beta=-0.0083$, Standardized $\beta=-0.0222, p=0.0615$ ), but had negative associations with LSA at levels 3 $(\beta=-0.0306$, Standardized $\beta=-0.0529, p<0.0001)$ and $4(\beta=-0.0372$, Standardized $\beta=-0.0477, p<0.0001)$, and a positive association with LSA at level 5 ( $\beta=0.0397$, Standardized $\beta=0.0401, p=0.0005$ ). 
A

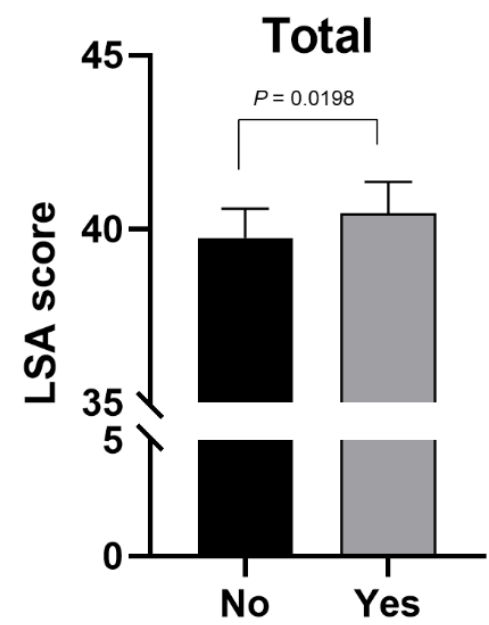

B

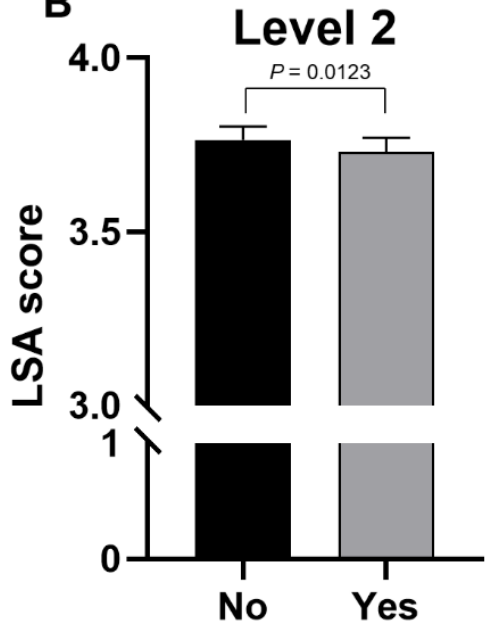

D

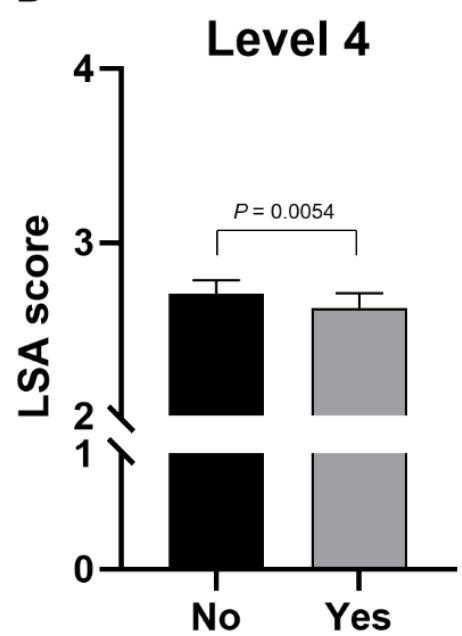

C

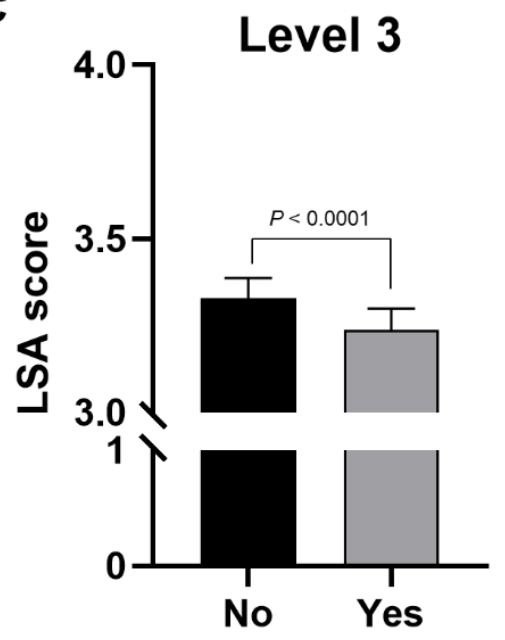

$\mathbf{E}$

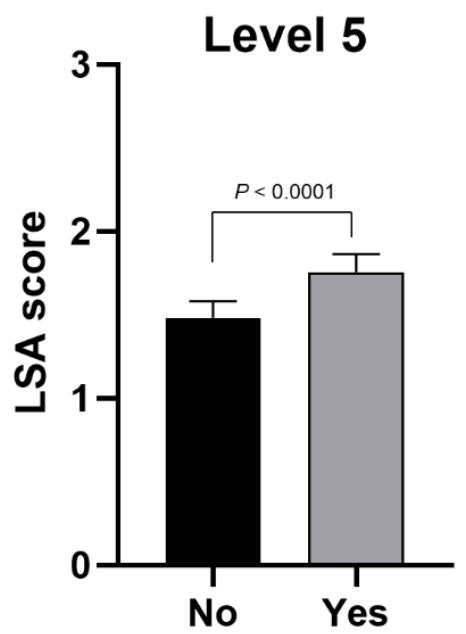

Figure 4. Associations of the state of emergency with measures of human mobility. (A), association of the state of emergency with LSAtotal; (B-E), associations of the state of emergency with LSA scores at each level. Bar graphs and error bars indicate mean and $95 \% \mathrm{Cl}$ in each category. Statistical analyses were performed using the general linear model with multiple comparison correction of the Turkey-Kramer method.

The rapid increase in new COVID-19 cases in each prefecture where the relevant area was located (i.e., ratio of new COVID-19 cases in the past month to total cases since the reporting of the first case in each prefecture) was associated with a lower LSAtotal score $(\beta=-0.1087$, Standardized $\beta=-0.0463, p<0.0001)$ and LSA at level $5(\beta=-0.0224$, Standardized $\beta=-0.0818, p<0.0001$ ) but was not significantly associated with LSA at levels $2-4$.

\subsection{Associations of Human Mobility with Subjective Happiness}

The LSAtotal score was significantly and positively associated with the GH score ( $\beta=0.0012 \pm 0.004, r=0.0376, p=0.0014$; Table 5 Model 1$)$ but not with the SHS score ( $\beta=0.0011 \pm 0.006, r=0.0214, p=0.0646$, Table 5 Model 1 ) after adjustment for gender, age, household income, occupation, residential area, marital status, child status, and anxiety about getting infected with COVID-19. However, the association between LSAtotal score and GH score disappeared after adjustment for personality, such as the measures of the TIPI-J and ER89. In addition, there were no associations between the SHS or GH scores and any level of LSA scores after adjustment for potential covariates including personality. 
Table 5. Associations of a score of LSAtotal with measures of subjective happiness.

\begin{tabular}{|c|c|c|c|c|}
\hline & & & Model 1 & $\begin{array}{c}\text { Model } 2 \\
\text { (Model 1 + Personality) }\end{array}$ \\
\hline \multirow[t]{5}{*}{$\mathrm{LSA}_{\text {total }}$} & \multirow{3}{*}{ Subjective happiness scale } & $\beta \pm S E$ & $0.00107 \pm 0.00058$ & $-0.00024 \pm 0.00051$ \\
\hline & & $r$ & 0.0214 & -0.00482 \\
\hline & & $p$-value & 0.0646 & 0.6353 \\
\hline & \multirow[b]{2}{*}{ General happiness (SUBI) } & $\beta \pm \mathrm{SE}$ & $0.00122 \pm 0.00038$ & $0.00016 \pm 0.00031$ \\
\hline & & $\begin{array}{c}r \\
p \text {-value }\end{array}$ & $\begin{array}{c}0.03762 \\
0.0014\end{array}$ & $\begin{array}{c}0.00479 \\
0.6195\end{array}$ \\
\hline
\end{tabular}

Model 1 included the variables of gender, age, household income, occupation, residential area, marital status, child status, and anxiety about contracting COVID-19. Model 2 included the variables of Model 1 and the variables of a ten-item personality inventory and ego resiliency. LSAtotal, the total score of the life space assessment questionnaire. SUBI, Subjective Well-being Inventory.

\section{Discussion}

The COVID-19 pandemic has led to a reduction in human mobility in Japan [18-21]. The government and other institutions have had to make swift political and medical decisions without established evidence and past experience. Therefore, the present nationwide study investigated the determinants, including personality, demographic, and environmental factors, of the inter-individual difference in human mobility during the pandemic in Japan to provide evidence for the next phase of COVID-19. This study was performed during the third wave (January 2021) of the pandemic in Japan. During this period, people's lifestyles began to change from the acute phase of the pandemic to the next stage, where people have begun to develop a new lifestyle to prevent the COVID-19 infection. For example, almost all leading companies have introduced work-from-home jobs depending on the occupational category. The state of emergency announcements and restrictions of human mobility have been based on several criteria established by the government and/or each local government. Therefore, our results can serve as evidence for a guide to a new lifestyle.

Our study revealed several features that might contribute to individual differences in human mobility. Notably, gender, occupation, vehicle use types, personality, and several types of living environments strongly contributed to the inter-individual variation in the LSAtotal score (Figure 5A).

In addition, the features likely varied depending on the level of life space (Figure 5B). To further interpret these associations, it would be necessary to consider that the features varied depending on the level of life space because the LSAtotal tends to be affected by the score of a wider range of life space due to its calculation method.

\subsection{Effects of Individual Factors on Human Mobility}

Once the demographic factors of human mobility during the pandemic are clarified, this should provide significant evidence on population groups requiring help. This study indicated that people who were men, middle-aged, and working had higher scores of LSAtotal and scores at almost all levels of LSA, implying that specific types occupations, such as an administrative position and manual labor, as well as essential workers, might contribute to greater human mobility. This result might suggest that even though workfrom-home was imposed in society, these individuals had to go to their workplace. The impact of gender and occupation on human mobility was consistent with the results during the early phase of the pandemic in Japan, as indicated by Hanibuchi et al. [7].

People living with their children also had higher LSAtotal scores and scores at almost all levels of LSA. This may be because they had to visit the grocery store more often and pick their children up from school as well as from leisure activities. In addition, younger people aged 20-39 years had relatively lower LSA scores. This might indicate that this generation can enjoy indoor life because of the popularization of video games or the Internet. 
A

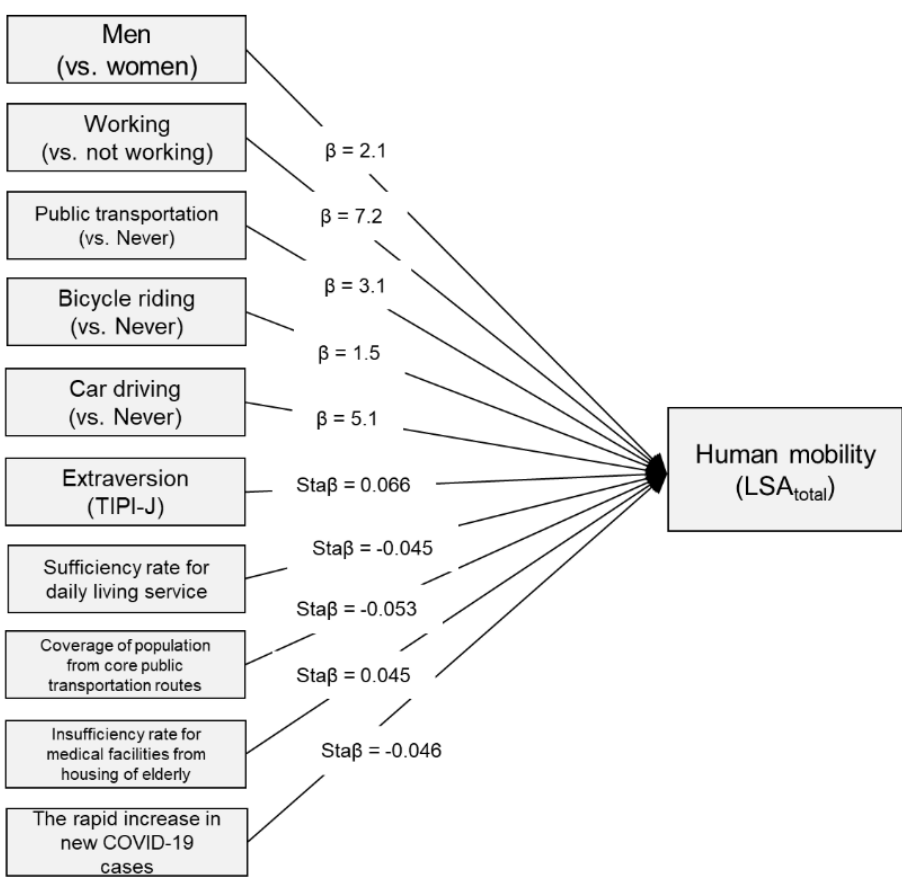

B

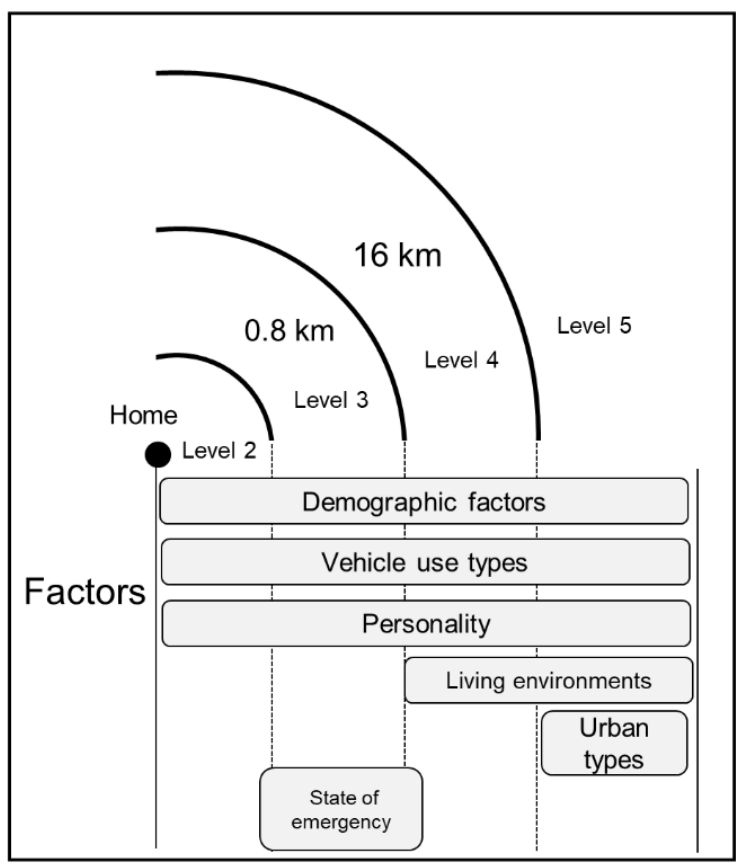

Figure 5. Summary of the major measures of human mobility. (A), the major factors of the total score of the life space assessment (LSA) questionnaire; (B), the effective ranges for the group of factors for each level of the LSA questionnaire. Factors were extracted based on the significance of the associations ( $p$-value $<0.0001)$.

Not surprisingly, people who used public transportation and rode bicycles had greater LSA scores, although a previous study indicated that there was no association between the use of public transportation and outings [7]. The association between bicycle riding and the LSA score disappearing at level 5 was also understandable. Although, as indicated by these results, vehicle use definitely contributes to the expansion of human mobility, the risk of infection by vehicle use requires further investigation.

As indicated by previous studies that personality factors, such as the Big Five, contribute to inter-individual variability in physical activity [22-24], our study revealed that the extraversion score and conscientiousness score was positively and was negatively associated with human mobility, respectively. In addition, our study found that ego resiliency as a factor of personality, which has received attention in the field of mental health, also had an association with human mobility. This is the first study to describe the associations between ego resiliency and human mobility, as well as personality and human mobility during the COVID-19 pandemic.

\subsection{Effects of Environmental Factors on Human Mobility}

Our study also revealed several environmental factors affecting human mobility during the pandemic. Notably, the variables of environmental factors around one's home had an impact on human mobility in areas far from the home. For example, insufficient daily living services within walking distance was associated with greater human mobility for the areas of LSA at levels 4-5. In addition, human mobility in the area where traffic on the roads between plains and mountains was high would be greater than in other areas. These results provide useful information for future urban development projects.

\subsection{Effects of COVID-19 on Human Mobility}

This study indicated that the impact of COVID-19 on human mobility depended on the area and the range of life space. Particularly, associations of the state of emergency with human mobility were varied at levels of life space in that, for the areas near the home, 
a state of emergency might have an impact on human mobility restriction, with no impact for the areas far from home. This might be explained by the fact that the areas under the state of emergency consisted of relatively larger cities. It is expected that people would commute a longer way than those living in areas without a state of emergency.

Although anxiety about being infected with COVID-19 had no impact on human mobility since the rapid increase in new COVID-19 cases was associated with lower human mobility, some subjective feelings might influence the related restriction.

\subsection{Effects of Human Mobility on Subjective Happiness}

Although several studies have pointed out that the pandemic $[25,26]$ and the lockdown associated with it [1-5] have worsened mental health and lowered happiness, our results did not indicate a clear association between human mobility and measures of subjective happiness after adjustment for personality. This implies that subjective happiness reflects a large inter-individual variability in personality and the impact of the pandemic on subjective happiness did not outweigh the impact of personality. The results of this study are understandable because of its cross-sectional analysis approach.

In addition, the impact on mental health was affected by the time period from the start of the pandemic. A previous study indicated that the effect on mental health gradually became apparent [2]. In Japan, it has been reported that the suicide rate was lower during the first phase of the pandemic but then increased [4]. Furthermore, for some people, restricted human mobility might improve subjective happiness by improving relationships among family members and QoL at home.

Therefore, further longitudinal studies are needed to clarify the association between reduced human mobility, related restrictions, and subjective happiness.

\subsection{Limitation}

Several limitations should be considered when interpreting the results of this study. First, because of its cross-sectional nature, we could not identify causality. Second, because our survey included online data, the assessment of human mobility was obtained using a subjective method. This might cause some misevaluation of the associations. Third, although our dataset had a relatively larger sample size from each area, it could not fully avoid sampling bias due to randomized anonymous sampling. This bias might lead to a misunderstanding of the association between environmental factors and human mobility. To support our results, further studies using objective methods for the assessment of human mobility are required.

\subsection{Summary of Factors That Increase/Decrease Human Mobility by Each Life Space}

For human mobility in the areas within the home and neighborhood, men, older adults aged 70-79 years, working individuals, those living with their children, public transportation users, bicycle users, and car drivers, including those who had a higher score of extraversion and ego resiliency and lower score of conscientiousness, and were living in an area where traffic on the roads between plains and mountains was high had a larger amount of human mobility. A higher population density in areas around train stations or bus stops for public transportation lines also had a negative impact on human mobility for areas ranging from the neighborhood to those far from home. In addition, the state of emergency lowered human mobility in the neighborhood. Transportation from one's home to the neighborhood is considered important for pursuing daily activities such as grocery shopping. To restrain the human traffic flow, the presence of environmental factors that could suitably support the individual factors would be ideal, but few meaningful relationships were found in this regard. By dispersing urban structures consisting of hubs with high road density, it may be possible to reduce the human traffic flow. In addition, although the population density in areas around train stations or bus stops for public transportation lines was negatively associated with the LSA scores at level 2, this 
association might be the result of an inherent fear of the COVID-19 infection and restraint from contact with too many people.

For the areas far from home, men, middle-aged individuals between 50-59 years, working individuals, public transportation users, and car drivers but not bicycle users, and those who had a higher score of extraversion and ego resiliency and a lower score of conscientiousness had a larger amount of human mobility. Furthermore, insufficient daily living services within walking distance and higher population coverage within walking distance from commercial facilities were associated with greater human mobility in areas far from home. In contrast, higher population coverage within walking distance from welfare facilities and core public transportation routes was associated with lower human mobility for areas far from home. In addition, the area where traffic on the roads between plains and mountains was high contributed to a larger amount of human mobility, whereas the area where there were many plains and road density was almost consistent was associated with lower human mobility for the areas far from home.

\section{Conclusions}

This study identified several factors that are determinants of human mobility during the COVID-19 pandemic in Japan. With regard to individual factors, including personality, our study revealed that gender, occupation, child status, vehicle use types, and specific personality types would be strong determinants of inter-individual differences. In particular, multi-aspect support is needed for people living with children during the pandemic. With respect to environmental factors, our study revealed that there is a lack of daily living services, including medical, welfare, and commercial facilities, and core public transportation routes, which increases human mobility in areas far from home. Thus, it is important to complement systems and/or services, such as home delivery services, to reduce the extent of human mobility in rural and suburban areas during the pandemic, in addition to urban reconstruction. However, even when these systems are developed, workers responsible for logistics and delivery are constantly needed in real time. It will also be necessary to investigate the construction of a system and urban design that will enable the minimum amount of human mobility and optimal logistics. Together, we suggest the necessity of making political decisions based on the characteristics of each area and individual, while also considering resilience measures against the pandemic and individual convenience for urban development.

Supplementary Materials: The following are available online at https:/ /www.mdpi.com/article/ 10.3390/su132313131/s1, Figure S1: Study flow chart.

Author Contributions: T.A., T.S. and Y.T. analyzed the data. T.A. prepared the manuscript. T.S., N.K., Y.T. (Yuji Takeda), M.A. and N.H. incubated the survey plan; T.S., Y.T. (Yen Tran), N.K., Y.T. (Yuji Takeda), M.A. and N.H. edited the manuscript. T.A., T.S. and N.H. had the primary responsibility for the final content. All authors have read and agreed to the published version of the manuscript.

Funding: This research was supported by the Ministry Economy of Trade and Industry, Japan.

Institutional Review Board Statement: Ethical review and approval were waived for this study, due to the anonymous online survey by the external institution.

Informed Consent Statement: Not applicable.

Data Availability Statement: The data are not publicly available; however, the data that support the findings of this study may be available from the corresponding author, T.A., upon reasonable request.

Acknowledgments: The authors thank all the staff and participants who engaged in this project.

Conflicts of Interest: The authors declare no conflict of interest. 


\section{References}

1. Gismero-Gonzalez, E.; Bermejo-Toro, L.; Cagigal, V.; Roldan, A.; Martinez-Beltran, M.J.; Halty, L. Emotional Impact of COVID-19 Lockdown Among the Spanish Population. Front. Psychol. 2020, 11, 616978. [CrossRef]

2. Gan, Y.; Ma, J.; Wu, J.; Chen, Y.; Zhu, H.; Hall, B.J. Immediate and delayed psychological effects of province-wide lockdown and personal quarantine during the COVID-19 outbreak in China. Psychol. Med. 2020, 1-12. [CrossRef]

3. Dragun, R.; Vecek, N.N.; Marendic, M.; Pribisalic, A.; Divic, G.; Cena, H.; Polasek, O.; Kolcic, I. Have Lifestyle Habits and Psychological Well-Being Changed among Adolescents and Medical Students Due to COVID-19 Lockdown in Croatia? Nutrients 2020, 13, 97. [CrossRef] [PubMed]

4. Tanaka, T.; Okamoto, S. Increase in suicide following an initial decline during the COVID-19 pandemic in Japan. Nat. Hum. Behav. 2021, 5, 229-238. [CrossRef] [PubMed]

5. Suzuki, Y.; Maeda, N.; Hirado, D.; Shirakawa, T.; Urabe, Y. Physical Activity Changes and Its Risk Factors among CommunityDwelling Japanese Older Adults during the COVID-19 Epidemic: Associations with Subjective Well-Being and Health-Related Quality of Life. Int. J. Environ. Res. Public Health 2020, 17, 6591. [CrossRef] [PubMed]

6. Roos, J.M.; Sprei, F.; Holmberg, U. Sociodemography, Geography, and Personality as Determinants of Car Driving and Use of Public Transportation. Behav. Sci. 2020, 10, 93. [CrossRef] [PubMed]

7. Hanibuchi, T.; Yabe, N.; Nakaya, T. Who is staying home and who is not? Demographic, socioeconomic, and geographic differences in time spent outside the home during the COVID-19 outbreak in Japan. Prev. Med. Rep. 2021, 21, 101306. [CrossRef] [PubMed]

8. Harada, K.; Shimada, H.; Sawyer, P.; Asakawa, Y.; Nihei, K.; Kaneya, S.; Furuna, T.; Ishizaki, T.; Yasumura, S. Life-space of community-dwelling older adults using preventive health care services in Japan and the validity of composite scoring methods for assessment. Nihon Koshu Eisei Zasshi Jpn. J. Public Health 2010, 57, 526-537. (In Japanese)

9. Oshio, A.; Abe, S.; Cutrone, P. Development, Reliability, and Validity of the Japanese Version of Ten Item Personality Inventory (TIPI-J). Jpn. J. Personal. 2012, 21, 40-52. [CrossRef]

10. Gosling, S.D.; Rentfrow, P.J.; Swann, W.B. A very brief measure of the Big-Five personality domains. J. Res. Personal. 2003, 37, 504-528. [CrossRef]

11. Hata, U.; Onodera, A. Development and Validation of a Japanese Version of the Ego-Resiliency Scale (ER89). Jpn. J. Personal. 2013, 22, 37-47. [CrossRef]

12. Block, J.; Kremen, A.M. IQ and ego-resiliency: Conceptual and empirical connections and separateness. J. Pers. Soc. Psychol. 1996, 70, 349-361. [CrossRef]

13. Sogabe, K.; Motomura, M. Subjective-happiness-feeling of university student in adolescent stage: Toward an exploration of its influential factors. Bull. Fac. Educ. 2010, 60, 81-87.

14. Lyubomirsky, S.; Lepper, H.S. A Measure of Subjective Happiness: Preliminary Reliability and Construct Validation. Soc. Indic. Res. 1999, 46, 137-155. [CrossRef]

15. Tonan, K.; Sonoda, A.; Ono, Y. Production of The Subjective Well-being Inventory Japanese Edition: It's Reliability and Validity. Jpn. J. Health Psychol. 1995, 8, 12-19. [CrossRef]

16. Nagpal, D.R.; Sell, D.H. Subjcetive Well-Being; World Health Organization: New Delhi, India, 1985.

17. National Land Numerical Information. In National Land Information Division, National Spatial Planning and Regional Policy Bureau, MLIT of Japan. Available online: https:/ / nlftp.mlit.go.jp/ksj/ (accessed on 30 January 2021).

18. Yabe, S.; Imanishi, K.; Nishida, K. Two-step seismic noise reduction caused by COVID-19 induced reduction in social activity in metropolitan Tokyo, Japan. Earth Planets Space 2020, 72, 167. [CrossRef]

19. Yabe, T.; Tsubouchi, K.; Fujiwara, N.; Wada, T.; Sekimoto, Y.; Ukkusuri, S.V. Non-compulsory measures sufficiently reduced human mobility in Tokyo during the COVID-19 epidemic. Sci. Rep. 2020, 10, 18053. [CrossRef]

20. Nagata, S.; Nakaya, T.; Adachi, Y.; Inamori, T.; Nakamura, K.; Arima, D.; Nishiura, H. Mobility Change and COVID-19 in Japan: Mobile Data Analysis of Locations of Infection. J. Epidemiol. 2021, 31, 387-391. [CrossRef]

21. Yamada, M.; Kimura, Y.; Ishiyama, D.; Otobe, Y.; Suzuki, M.; Koyama, S.; Kikuchi, T.; Kusumi, H.; Arai, H. Effect of the COVID-19 Epidemic on Physical Activity in Community-Dwelling Older Adults in Japan: A Cross-Sectional Online Survey. J. Nutr. Health Aging 2020, 24, 948-950. [CrossRef]

22. Artese, A.; Ehley, D.; Sutin, A.R.; Terracciano, A. Personality and actigraphy-measured physical activity in older adults. Psychol. Aging 2017, 32, 131-138. [CrossRef]

23. Kekalainen, T.; Laakkonen, E.K.; Terracciano, A.; Savikangas, T.; Hyvarinen, M.; Tammelin, T.H.; Rantalainen, T.; Tormakangas, T.; Kujala, U.M.; Alen, M.; et al. Accelerometer-measured and self-reported physical activity in relation to extraversion and neuroticism: A cross-sectional analysis of two studies. BMC Geriatr. 2020, 20, 264. [CrossRef] [PubMed]

24. Ohmori, Y.; Suzuki, N.; Morita, A.; Aiba, N.; Miyachi, M.; Watanabe, S.; Kikuchi, Y.; Kimira, M. Association of Personality (NEO-Five Factor Inventory) with Eating Behaviors and Physical Activity Levels in Obese Subjects in the Saku Control Obesity Program (SCOP). Anti-Aging Med. 2007, 4, 43-50. [CrossRef]

25. Gawrych, M.; Cichon, E.; Kiejna, A. COVID-19 pandemic fear, life satisfaction and mental health at the initial stage of the pandemic in the largest cities in Poland. Psychol. Health Med. 2021, 26, 107-113. [CrossRef] [PubMed]

26. Zhao, S.Z.; Wong, J.Y.H.; Luk, T.T.; Wai, A.K.C.; Lam, T.H.; Wang, M.P. Mental health crisis under COVID-19 pandemic in Hong Kong, China. Int. J. Infect. Dis. 2020, 100, 431-433. [CrossRef] [PubMed] 